\title{
The Final Stages of Protein Synthesis and the Role of Lipids in the Process
}

\author{
BY G. D. HUNTER \\ Agricultural Research Council Field Station, Compton, Berkshire \\ AND G. N. GODSON \\ Chester Beatty Research Institute, Institute of Cancer Research, \\ Fulham Road, London, S.W. 3
}

It is now a well-known fact that protoplasts prepared by the action of lysozyme on Bacillus megaterium can under suitable conditions carry out many of the functions of the intact cell. Thus they can respire, grow, form spores and synthesize nucleic acids and proteins when incubated in media of high osmotic pressure. In more dilute media, the protoplasts can readily be lysed with the liberation of about $70 \%$ of their dry weight in a soluble cytoplasmic fraction. The remainder of the protoplast can be completely sedimented under moderate centrifugal forces as a membrane complex which appears to consist of two principal components when viewed in the electron microscope (Godson, Hunter \& Butler, 1961). One component consists of large empty membranous vesicles; many sections seen, however, are almost entirely populated by smaller vesicles which appear to be studded with electron-dense particles of approximately $150 \AA$. diameter. While the larger vesicles are almost certainly derived from the cytoplasmic membrane of the cell, the smaller ones may partly originate from internal structures.

When protoplasts are incubated with labelled amino acids for short periods of time up to $2 \mathrm{~min}$. and then lysed, the bulk of the labelled protein formed is found in this membrane complex. The isolated membrane complex is itself capable of incorporating labelled amino acids into protein in vitro, although the observed incorporation rate is linear with time and can continue in this way for several hours. Degradative experiments have clearly shown that the bulk of the label is bound in polypeptide form (Hunter, Brookes, Crathorn \& Butler, 1959). Similar results have been reported by Spiegelman (1959) and by Zillig and his co-workers (Schachtschabel \& Zillig, 1959; McCorquodale \& Zillig, 1959), using Escherichia coli, and by Connell, Lengyel \& Warner (1959) using Azotobacter.

The appearance of the membrane complex in the electron microscope led us to suspect that it contained bound ribonucleoprotein particles of the type that have been implicated in other systems as being directly concerned in protein synthesis, and our more recent work (Godson et al. 1961) has been directed towards the further fractionation of this complex.

The most effective method used has involved the dispersal of the complex in a dilute buffer under the impact of ultrasonic vibrations. The dispersed material can now be readily resedimented in two distinct layers, leaving about $24 \%$ of its dry weight in the supernatant fraction. The two layers can be separated quite simply by mechanical means, the lower heavy white layer consisting largely of non- 
proteinaceous material which need not concern us here. The upper layer, which analyses chemically as mainly phospholipoprotein with small amounts of RNA, appears in the electron microscope as small, rather ghostly, vesicles. No dense particles are visible, such as, for instance, were seen in the preparations of the original membrane complex or as can be seen clearly in electron micrographs of the whole cell. However, density gradient centrifugation of the supernatant fraction from the ultrasonic treatment readily yields ribonucleoprotein particles of sedimentation constants 45 and 30 , leaving finally in solution material containing protein and nucleic acids of very low sedimentation constant.

Thus, if labelling experiments are carried out in the intact protoplast, four significant protein fractions can subsequently be obtained by this procedure: the initially formed cytoplasmic fraction; and from the membrane complex, ribonucleoprotein particles, the phospholipoprotein fraction and protein solubilized by the ultrasonic treatment (5S protein). Rather surprisingly, such experiments clearly show that the bulk of the labelled protein resides at early times in the phospholipoprotein fraction. The level found in the ribonucleoprotein particles is somewhat variable from experiment to experiment, but always less during the first minute than that found in the phospholipoprotein. The cytoplasmic fraction and the probably related $5 S$ protein acquire label at later times, and 'chaser' experiments, where the dose of labelled amino acid is followed after a few seconds with a much larger dose of ${ }^{12} \mathrm{C}$-amino acid, indicate that its label is derived from the phospholipoprotein fraction. We were, however, unable to obtain any evidence from these 'chaser' experiments indicating that the labelled protein in the phospholipoprotein fraction was derived from the ribonucleoprotein particles. In this connexion, it is of interest that Mitsui (1961) has recently described the incorporation of labelled amino acids into cytochrome $c$ in a related cell-free system from a pseudomonad. The protein was isolated in a pure state, and Mitsui (personal communication) finds no labelled cytochrome $c$ bound to free ribonucleoprotein particles.

However, recent work from other laboratories has indicated that only a small proportion of $\mathbf{7 0 S}$ ribonucleoprotein particles are directly concerned in protein biosynthesis, and our phospholipoprotein fraction does contain up to $2 \%$ of RNA. It is possible that the ribonucleoprotein particles isolated elsewhere are obtained in our delicate fractionation procedure in a bound form attached to the phospholipoprotein surface. This surface might then be concerned merely in the rapid removal of newly synthesized protein from the ribonucleoprotein. This could account for the fact that the protein synthetic abilities of isolated ribonucleoprotein particles are, in general, rather small.

On the other hand, the phospholipid surface might have a rather more direct role to play. One of the difficulties of the hypothesis of protein synthesis as expounded by Zamecnik, Hoagland and others (Zamecnik, 1960) is that the transfer RNA molecules when transferred to the ribosomal surface appear to be too long and complex to serve in their entirety as suitable transfer agents. It was this difficulty, combined with our experimental results, that led us to propose a mechanism for the final stages of protein biosynthesis which has been described in more detail elsewhere (Hunter \& Godson, 1961). We assume that the specific ordering of the transfer RNA molecules, and hence of the amino acid residues, is determined by specific hydrogen bonding with the ribosomal RNA, by some such mechanism as that out- 
lined by Crick, Griffith \& Orgel (1957). If this linkage takes place at the same distance down the transfer RNA chain for all types of transfer RNA molecule, then a surface with a sequence of charged phosphate groups placed at approximately that distance from the ribosomal surface could make contact with each transfer RNA chain at relatively closely defined points. It was suggested that a phospholipid surface spatially orientated in this manner could serve to hydrolyse the amino acids from their binding to the terminal nucleotide residues of the transfer RNA molecules with the preservation of their bond energy, so that the formation of the peptide chain would proceed spontaneously and rapidly.

The same type of considerations, however, might apply if 'messenger-RNA' should prove to be of general occurrence. In this case, it could be postulated that the transfer RNA molecules bind initially not to the ribosomal RNA but to the messenger RNA, with the ribosomal RNA taking the place of the phospholipid surface. This would account for the finding of 'nascent' protein directly on the ribosomal surface in the experiments described by Dr McQuillen and others. However, another possibility is that most methods of cellular fractionation tend to destroy delicate phospholipid surfaces and membranes, in which case any protein originally fixed between phospholipid and ribonucleoprotein surfaces, would then be found on the ribosomes alone.

To turn to another aspect, one of the consequences of our own hypothesis would be the transient existence of lipo-amino acid complexes in the course of the transfer of the amino acid residues from transfer RNA to the phospholipid surface, and these might accumulate in special circumstances. Lipo-amino acid complexes have been detected by several groups of workers in recent years (Hendler, 1959, 1961; Gaby, Naughten \& Logan, 1959; Gaby \& Silberman, 1960; Gaby, Wolin \& Zajac, 1960; Wallach, Soderberg \& Bricker, 1960; Bogoch, Belval \& Winer, 1961; Fukui \& Axelrod, 1961), and rapidly metabolizing compounds of this type are best isolated from protoplasts of Bacillus megaterium by acetone extraction which leaves the bulk of the phospholipids undissolved. It is a pity that so little progress has been made towards a more precise chemical definition of these complexes. However, complexes have been separated from free amino acids by chromatographic (Hunter \& Goodsall, 1961), electrophoretic (Gaby et al. 1960) and counter-current methods (Hendler, 1961). In the case of B. megaterium the complexes can be separated from free amino acids on a semi-preparative scale by paper chromatography. On a larger scale, the complexes were separated from other lipids by successive chromatography on silicic acid and DEAE-cellulose, the last fractionation effecting a separation of the complexes into phosphorus-free and phosphorus-containing fractions. Both the principal fractions gave fatty acids on hydrolysis, but very little serine, ethanolamine or choline was detected. Small amounts of glycerol and carbohydrates were found, but it is not as yet possible to propose any chemical structures for these materials.

Whatever the precise chemical nature of these lipo-amino acid complexes, there seems to be little doubt that the amino acid residues bound to them can readily be used for protein biosynthesis (Hunter \& Goodsall, 1961). The role of these compounds is, however, by no means established, and they may perhaps serve as a store of activated amino acids. Gaby, on the other hand, has recently suggested (Gaby et al. 1960) that the complexes studied in his laboratory are primarily concerned in amino acid transport. 


\section{REFERENCES}

Bogoch, S., Belval, P. C. \& Winer, D. (1961). Hot methanol extraction of human brain aminoglycolipids. Nature, Lond. 190, 152.

CONNELI, G. E., LENGYeL, P. \& WARNER, R. C. (1959). Incorporation of amino acids into protein of Azotobacter cell fractions. Biochim. biophys. Acta, 31, 391.

Crick, F. H. C., Griffith, J. S. \& Orgel, L. E. (1957). Codes without Commas. Proc. nat. Acad. Sci., Wash. 43, 416.

FUKUI, T. \& AxeLrod, B. (1961). Enzymatic formation of lipo-amino acids by rat liver preparations and the nature of the product. J. biol. Chem. 236, 811.

Gaby, W. L., Naughten, R. N. \& Logan, C. (1959). The role of phospholipides in the metabolism of amino acids by the mold Penicillium chrysogenum. Arch. Biochem. Biophys. 82, 34.

Gaby, W. L. \& Silberman, R. (1960). The role of phospholipides in the metabolism of amino acids. II. The incorporation of leucine and tyrosine in liver phospholipides. Arch. Biochem. Biophys. 87, 188.

GaBY, W. L., Wolin, H. L. \& ZAJAC, I. (1960). The role of phospholipides in the uptake of amino acids by Ehrlich ascites carcinoma cells. Cancer Res. 20, 1508.

Godson, G. N., Hunter, G. D. \& Butler, J. A. V. (1961). Cellular components of Bacillus megaterium and their role in protein biosynthesis. Biochem. J. 81, 59.

HeNDler, R. W. (1959). Passage of radioactive amino acids through 'nonprotein' fractions of hen oviduct during incorporation into protein. J. biol. Chem. 234, 1466.

HENDLer, R. W. (1961). Some properties and the possible metabolic significance of amino acid-lipid complexes. Biochim. biophys. Acta, 49, 297.

Hunter, G. D., Brookes, P., Crathorn, A. R. \& Butler, J. A. V. (1959). Intermediate reactions in protein synthesis by the isolated cytoplasmic-membrane fraction of Bacillus megaterium. Biochem. J. 73, 369.

Hunter, G. D. \& Godson, G. N. (1961). Later stages of protein synthesis and the role of phospholipids in the process. Nature, Lond. 189, 140.

Hunter, G. D. \& Goodsalx, R. A. (1961). Lipo-amino acid complexes from Bacillus megaterium and their possible role in protein synthesis. Biochem. J. 78,564 .

McCorquodale, D. J. \& Zillig, W. (1959). Untersuchen zur Biosynthese der Proteine, II. Uber die Verteilung der aminosäureaktivierenden Enzyme in Zellfraktionen aus Homogenaten von Escherichia coli B. Z. physiol. Chem. 315, 86.

MrTsur, H. (1961). Incorporation of amino acids into cytochrome $\mathrm{c}$ in a bacterial cell-free system. J. Biochem., Tokyo, 49, 411.

Schachtschabel, D. \& Zillig, W. (1959). Untersuchen zur Biosynthese der Proteine, I. Über den Einbau 14C-markierter Aminosäuren ins Protein zellfreier NucleoproteidEnzym-Systeme aus Escherichia coli. B. Z. physiol. Chem. 314, 262.

Spiegelman, S. (1959). Protein and nucleic acid synthesis in subcellular fractions of bacterial cells. Recent Progr. Microbiol. 7, 82.

Wallach, D. F. H., Soderberg, J. \& Bricker, L. (1960). The phospholipides of Fhrlich ascites carcinoma cells. Composition and intracellular distribution. Cancer Res. 20, 397.

ZAMECNIK, P. C. (1960). Historical and current aspects of the problem of protein synthesis. Harvey Lect. 54, 256. 